\title{
Nuclear Energy for Sustainable Economic Development
}

\author{
F. D'Auria, A. Bousbia Salah \\ Dipartimento di Ingegneria Meccanica, Nucleare e della Produzione, Pisa, Italy \\ Email: f.dauria@ing.unipi.it
}

Received 11 February 2016; accepted 14 August 2016; published 17 August 2016

Copyright (C) 2016 by authors and Scientific Research Publishing Inc.

This work is licensed under the Creative Commons Attribution International License (CC BY). http://creativecommons.org/licenses/by/4.0/

c) (i) Open Access

\begin{abstract}
The discovery and the application of nuclear energy constitute the most important technological achievement of the past century. However, the development and the exploitation of this technology have been remarkably smaller than foreseeable. An overview of the significant features of the nuclear technology including the comparison with competitive energy sources is made. The "embedded" safety engineering and the pollution are discussed and the main features are mentioned. Indeed, nuclear technology can be applied for the sustainable society development by producing substantial amount of clean water from the ocean. The idea is to build up nuclear power plant sites that produce desalinated water and pump it several tens of kilometers away to form a lake into a desert region. This could help to establish the conditions for an agriculture-based civilization.
\end{abstract}

\section{Keywords}

Nuclear Energy, Sea Water Desalination, Economic Development

\section{Introduction}

The nuclear energy constitutes the most relevant discovery of the past century. This can be compared with the discovery of the fire and is also sometimes referred as "nuclear fire" to distinguish it from the "chemical fire" available to the humanity several millennia before. The chemical fire can be used to burn the house of the neighbor, or to prepare food, or to construct cars, or to produce electricity. The first utilization does not justify the ban for the other uses. The "non-limited" and much more powerful "nuclear fire" (compared with the chemical fire) is not adequately exploited by this civilization because of its initial use as a mass-destructive weapon. The same civilization, for its overwhelming energy needs, appears satisfied for burning in a few tens of years amounts of fossil fuels accumulated by the nature during the course of millions of years. The production of pol- 
lutants, that accompanies the chemical burning, might be seen as a minor problem compared with the disappearance of such a natural resource.

The number of fatalities and the environmental impact, unavoidably associated with any energy source, must be at the basis for designing a consistent share of energy sources. The actual cost of energy should have a role inside a broader context where the available natural resources and the level of technological development of individual countries are properly considered.

Other than the number of fatalities and the environmental impact, two major considerations should drive the industrialized countries toward a more profitable consumption of nuclear energy:

- The use of nuclear energy preserves the consumption of fossil materials produced on the earth during hundreds million years, avoiding their full burning in less than a century. Power from fissile elements ensures the energy survival for a period of the order of $10^{4}$ years.

- Fossil fuel burning should be left to the less developed countries. Consumption of low technology fuel (i.e. the fossil fuels, mostly produced in the less developed countries) by industrialized countries contributes to enlarging the existing gap between countries and civilizations.

The purpose of the paper is to provide a view about the current status of the nuclear technology by streamlining the attention toward emblematic topics that are discussed in a provocative way. The scientific rigor, needed when energy problems are considered, may not be found from the performed analysis (references are avoided to stress the "spreading" nature of the memory). Nevertheless, the out-comings of the study are expected to be useful for open minds willing to support the nuclear energy option in the present civilization and to protect the environment from the products associated with the chemical fire when adopted for electricity production [1].

The fight against the conditions that prevented the suitable exploitation of the nuclear energy has been lost at the time being within the industrialized countries. In order to remove the established conditions, an attempt is made here to propose, in a merely academic way, a unique application for the nuclear technology [2]. Producing substantial amounts of clean water from the ocean could help establish the conditions for an agriculture-based civilization in the desert areas of the planet. The analysis outlined in the paper has been carried out for a desert land as Algeria. The idea is to find a dry or seasonal river that originates from a dry lake and ends up into the sea. The sea water could be pumped towards a nuclear power desalination site, which in turns feeds the dry lake by desalinated water. Conditions are created in this way to develop a human civilization based upon the autonomous agriculture resources around the river and the lake. The benefit of using nuclear technology for providing water resources around a dry river is emphasized.

\section{Nuclear Technology: The Main Features}

The features of the nuclear technology constitute by themselves an emblematic topic: an impartial judge will state that these typical and unique characteristics are beneficial for the development of the human civilization [3]. In order to boast such positive peculiarities, nuclear technologists undertook an unprecedented effort and many branches of learning were explored: mathematics, physics, chemistry, thermal hydraulics, neutronics, material technology, computer science, electronics, robotics, safety engineering, risk analysis, quality control procedures, quality assurance and many other disciplines are concerned.

Thanks to this effort, many branches of learning have born and other existing branches have been developed, exploited and strengthened to such an extent to contribute to the technological development of the world. This is a unique, cannot-say-how-much-positive feature of the nuclear technology, as outlined by Figure 1.

Unless nuclear technology typical features are objectively positive, detractors usually use them to 'prove' that the technology is unsafe, non-competitive, non-economic, polluting, in a word, immoral. Probably they don't know what a proof is. Anyway, let's briefly analyze some of these features.

\subsection{Energy Competition}

Existing nuclear power plant technology has been compared with both renewable and non-renewable energy technologies, with both consolidated/state of the art or developing technologies. Such a characterization could involve a large number of aspects, but only a few have been provocatively considered. The addressed items do not allow a comprehensive or systematic or subjective comparison. Rather, significant aspects that distinguish the technologies are mentioned that are improperly used to run nuclear down. 


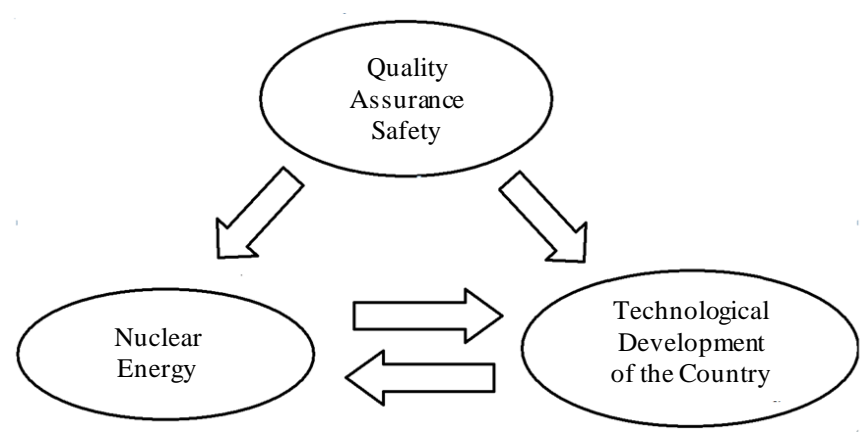

Figure 1. Role of nuclear technology in the development of the civilization.

\subsubsection{Nuclear vs. Hydropower}

The hydropower exploitation implies the construction of dams that unavoidably impact the surrounding animal and plant life. Huge territory extensions are needed to generate electricity from dams, as discussed in the section "Environment Protection". Alternatively, dams can be built in mountain regions creating the potential for enormous disaster. In addition, suitable natural conditions for the construction of dams may occur thousands kilometers far from the energy consumption location. As a consequence, substantial amounts of energy are lost and an additional impact on the territory is caused by the energy transportation.

\subsubsection{Nuclear vs. Solar}

Solar energy is generally made in desert areas that are located, again, away from the important energy consumption centers. In economic terms, both solutions are not (yet) competitive with other energy sources. If non-desert areas are used, these are allotted to become desert. Toxic materials must be manipulated when electronic cells are used. Energy storage (strictly needed to allow energy consumption when the sun is obscured by clouds or by the earth motion) also requires the use of pollutant materials [4].

\subsubsection{Nuclear vs. Wind}

Wind mills are suitable to generate electricity with reduced coasts. Their installation in the desert areas of the planet causes increase of cost that, in any case, is not (yet) competitive with other energy sources. Unfortunately, hundreds wind mills have been installed in beautiful areas of the planet, forgetting landscape impacts. The majority of these areas were not accessible to cars: the installation of the wind mills implied the construction of the roads and the consequent irreversible degradation of the nature. As in the case of sun, energy storage (strictly needed to allow energy consumption when the wind is not strong enough) also requires the use of pollutant materials [4].

\subsubsection{Nuclear vs. Fossil (Coal, Oil, Gas)}

From the economic point of view, fossil fuels constitute the only competitive energy source. Drawbacks, related to the nuclear energy source, which apply to a different extent for any of the coal, oil or gas fuels are recalled in the following.

The amount of fuel needed (either in volume or in mass terms) to produce the unit electric energy is million times larger.

- Hundreds peoples die per year just owing to transportation of suitable amounts of fossil fuels. Huge territories of the earth have been irreversibly contaminated owing to the transportation of fossil fuels.

- Hundreds peoples die per year just owing to the extraction of suitable amounts of fossil fuels. Explosions of coal mines cause fatalities that sum up with cancer deaths of miners and in cities close to the mines.

- Hundred thousand deaths per year are addicted to the pollution causes by burning of fossil fuels.

- Irreversible consumption of the fuels that were formed in chemical processes lasting million years happens in less than a century.

\subsection{Safety and Residual Risk}

Design of application and safety could only be developed in parallel. Any design concept was not considered if 
safety concern could be raised. Authorities controlling the design were created in any nation involved with the technology. Their only purpose was to prevent any design that could have any reasonable possibility to endanger the environment or the population.

Without having the objective to go into detail into the meaning of safety, an overview is given hereafter of the safety issue as presently considered. Then, examples are provided in relation to the values of 'safety indicators' for the nuclear technology that are compared with safety indicators of other technologies that are fully accepted in the present civilization. As shown in Table 1, the energy system with by far the greatest amount of controversy about its risk is undoubtedly nuclear power [5]. Actually, Chernobyl and Fukushima accidents "killed" together less than one hundred persons, but possibly prolonged the life to million peoples.

\subsubsection{Overview of the Safety Issue}

The safety of nuclear power plants (NPP) is based on the defense in depth concept, which relies on subsequent physical barriers (fuel matrix, cladding, primary system pressure boundary, containment) and other provisions to control radioactive materials and on multiple levels of protection against damage to these barriers and against undue radiological impact on the NPP itself and on its surroundings. Demonstration that there is no undue risk caused by plant operation is obtained by means of safety assessment.

Safety assessment is a broad term dealing with the systematic processes aimed at ensuring that all relevant safety requirements are met. These cover the various aspects connected with the siting, the design, the construction, the operation including the maintenance and the qualification of the involved personnel and the decommissioning of any NPP.

The entire range of conditions for which an NPP is designed according to established design criteria, including all the national regulatory requirements, and for which the damage to the fuel and the release of radioactive material are kept within authorized limits, form the design basis of an NPP [3]. Within the design basis, a number of unintended events are considered, including operating errors and equipment failures, whose consequences or potential consequences are not negligible in terms of safety. According to the probability of its occurrence and potential consequences, an event may be classified as an anticipated operational occurrence or a Design Basis Accident (DBA).

An accident occurring outside the NPP design basis is called a Beyond Design Basis Accident (BDBA). A beyond design basis accident may or may not involve degradation of the reactor core (leading to significant core damage). An accident involving core degradation (typically core melt) is also called a severe accident. It must be noted that such event causes a huge capital lost and is not expected to cause harms to the population because the 'fourth barrier' is designed to protect the environment (including the human being) against such an event.

Safety assessment includes safety analysis as an essential component. By the term safety analysis, an analytical study is meant by which it is demonstrated how safety requirements, such as ensuring the integrity of barriers against radioactive releases and various other requirements, are met for initiating events (both internal and external) occurring in a suitable range of operating conditions, and in other circumstances, such as varying availability of the plant systems.

Accident analysis is an important tool for confirming the adequacy and efficiency of provisions in the defense in depth concept to cope with challenges to plant safety. It is used in a number of applications, such as licensing of a new plant, modification of an existing plant, periodic safety reviews, etc.

\subsubsection{Comparison among Safety Indicators and Off-Nominal System Performance}

All machines and systems designed by human brain are subject to fail and everything that surrounds us consti-

\begin{tabular}{ccc} 
Table 1. Risk per unit energy output (1969-2000) [5]. & \\
\hline Energy chain & Accidents & Fatalities \\
\hline Coal & 1119 & 20,276 \\
Oil & 375 & 20,218 \\
Nuclear & 2 & 31 \\
Natural Gas & 135 & 2043 \\
Hydro & 12 & 29,935 \\
\hline
\end{tabular}


tutes a machine or a system, i.e. from houses, to bridges, to TV screens, to cars, to guns, to airplanes. No system is designed to fail and "off-nominal" system performance implies a failure. The probability to fail and the damage produced to the environment owing to the failure distinguish the various possible failures.

What distinguishes the various technologies, or even the individual machines and systems, in relation to risk is listed below:

- probability of occurrence of an environment harmful event,

- damage associated to the event expressed in terms of human deaths,

- knowledge and acceptance of the risk.

Typical results from that report is that risks coming from smoking, from travelling by car, by plane, by train, by ship etc. or due to natural events are much larger than any conceivable risk associated with the existence of whatever large number of nuclear power plants.

In the forthcoming years it was clear that the death owing to the consumption of tobacco, or of alcohol, or the pleasure to drive a car in a dangerous environment was among the freedom of individuals who could get a pleasure from the planned desire, while the death eventually caused by harmful radiation was to be addicted to benefits for the entire society and therefore "less acceptable".

In the case of Chernobyl and/or Fukushima, there is no study showing that the number of deaths owing to the accidents caused a number of late fatalities for any reasonable group of population outside the statistical tolerance range. Studies conducted by scientific institutions show the opposite.

\subsection{Environment Protection}

The evaluation of the impact upon the environment brings to the best evaluation of the nuclear technology compared with any other technology suitable for electrical energy production. The issue of environment protection is huge in terms of indicators, social impact, costs, global climate change and potential harmful consequences. Any energy source has an impact upon the environment. This must be evaluated considering the various stages of developing, exploiting and decommissioning the technology.

In the case of fossil fuel technology and making reference to coal at first, environmental impact includes, but is not limited to drilling a mine, diffusion to the atmosphere of gases and particulate from the mine, transportation of miners to the mine, cleaning of the coal from the mine, transportation of the coal from the mine to the steaming plant, production of gases and solid particulate at the chimney of the plant, production and transportation of ashes.

Energy sources, like geothermal, wind, hydro, solar are impact-free only to some mass-media or following ignorant institutions. Namely, radioactive pollution caused by a geothermal plant may be order of magnitudes larger than the pollution (in terms of activity) due to a nuclear power plant. In addition various acids are extracted from the underground together with steam, as already mentioned. Wind energy determines irreversible impact on the ground. In the South of Italy, thousands “wind-mills” are installed along several hundred miles on the top of beautiful Appennino's hills (more than 1000 m elevation on the sea level) that before were inaccessible to cars, and tens of miles apart from the nearest road. Now these lands are open to cars and to the human impact. Hydro power implies the flooding of hundreds or thousands square kilometers. On average, making reference to the Itaipu hydro power station, i.e. the biggest hydro-plant in the world installed at the border between Argentina, Brazil and Paraguay, the production of $1 \mathrm{MWe}$ (on the site) requires more than $10^{5}$ square meters. The production of the same power in a nuclear plant requires about 500 square meters (i.e. 200 times less). Normally the ground around dams is not a desert and is excellent for agriculture.

NPP do not emit any pollutant during the operation. Only water is emitted in the form of droplets from cooling towers or owing to the increased evaporation of water reservoirs adopted to cool the condenser. Radioactivity connected with noble gases is only emitted by the power plants (less than 1/5 of the total number of power plants) equipped with boiling water reactors with amounts about 100 times less than allowed by regulations and lower than released by some hospitals.

\section{Proposal for "Civilization-Sustainable" Deployment}

It is well known that most of the ancient civilizations that brought to the present development for the human societies developed along rivers: the ancient Egyptians around the Niles, the Babylonians between the Tigris and the Euphrates, the Romans along Tevere, the Etruscans along the Arno and the Chinese along the Yellow River, 
just to name some of the best known examples.

Developed societies tend to transfer to underdeveloped societies currency. The underdeveloped society supplements the received currency with any raw strategic matter that may offer and buy technological goods from the developed societies. In this way, at the end of the process (i.e., receiving currencies, delivering raw matters and buying goods for the underdeveloped countries) the developed societies have all the currency and all the strategic raw matters in their possession.

The effective help for these countries is to supply them with the tools necessary to exploit the resources which they dispose of and to supply the conditions which allow this exploitation. We must supply them with a hoe and teach them how to use it, not supply them with vegetables posing as magnanimous.

Authors of this paper do think that the pacific use of nuclear energy might be a smart hoe. More precisely, nuclear technology not only can help but constitutes the only technology that can be suited for the plan. It is proposed to transfer from developed to under-developed societies, the means to sustain the development i.e. not the apparent product of the development constituted by the currency.

In addition, the water needs and the fact that the poorest societies actually live in the desert areas of the planet are considered. Having this in mind the proposal is simple: to provide the condition to create a 'new' river suitable for the rise of plantation in the desert to such an extent to sustain the creation of a people and of a civilization.

An academic and provocative proposal is formulated and minor resources (in the sense of devoted effort not sufficient even for a preliminary technological project) have been invested so far. Many questions probably are lightening in the reader's brain: "why to create such a civilization" or "where to create such a river" or "who might do such a huge work" and, especially, "how to create a river in the desert" and "which technology is so powerful to make of a such strange and extravagant proposal a realistic scenario and an interesting issue, which might induce someone to reflect".

\subsection{The Task}

The task is to find out a suitable coastal site close to a desert area of Africa and to build-up a certain number of nuclear power plants (see Figure 2). Desalinated seawater should be produced and pumped several tens of kilometers away of to form a lake into the desert. A dry river originating from the lake should end up into the sea very far from the coastal nuclear site. In this way, conditions are created to develop a human civilization based upon the autonomous agriculture resources around the river and the lake.

The analysis outlined in the next section has been carried out having in mind a five million population that should occupy a suitable territory and have sufficient water resources for a self-sustained farming.

Algeria, has been chosen where all the aforementioned conditions exit. Figure 2 shows the location of the considered desert land around which a dry river that can be fertilized thanks to nuclear energy resources.

\subsection{Technical Data to Exploit the Idea}

Even though the proposal is provocative and academic, a limited scope and rough technical evaluation has been performed.

The first step leads to fix the specifications. This is outlined in Table 2. Agriculture products should be cultivated around the dry river. The civilization should grow at some distance from the energy production that should remain in a remote area for strategic and security reasons (easy to protect possible opponents to the civilization). In order to exploit the idea, a number of assumptions must be formulated that constitutes the second step for the study. The main assumptions are listed in Table 3.

In the third step of the study simplified calculations have been carried out considering the above assumptions. The main results are given in Table 4. The information in the last row can be further elaborated. If one assumes the cost of a reference standard NSSS unit equal to 2 billion US \$, the overall pro-capita cost to sustain a new civilization of 5 million people results less than 3000 US $\$$. The additional rough assumptions of negligible fuel costs and of design lifetime for the NSSS units equal to the average human life have been made.

\section{Conclusions}

All energy sources are needed for the "sustainable" development of the mankind. Competition should be in- 


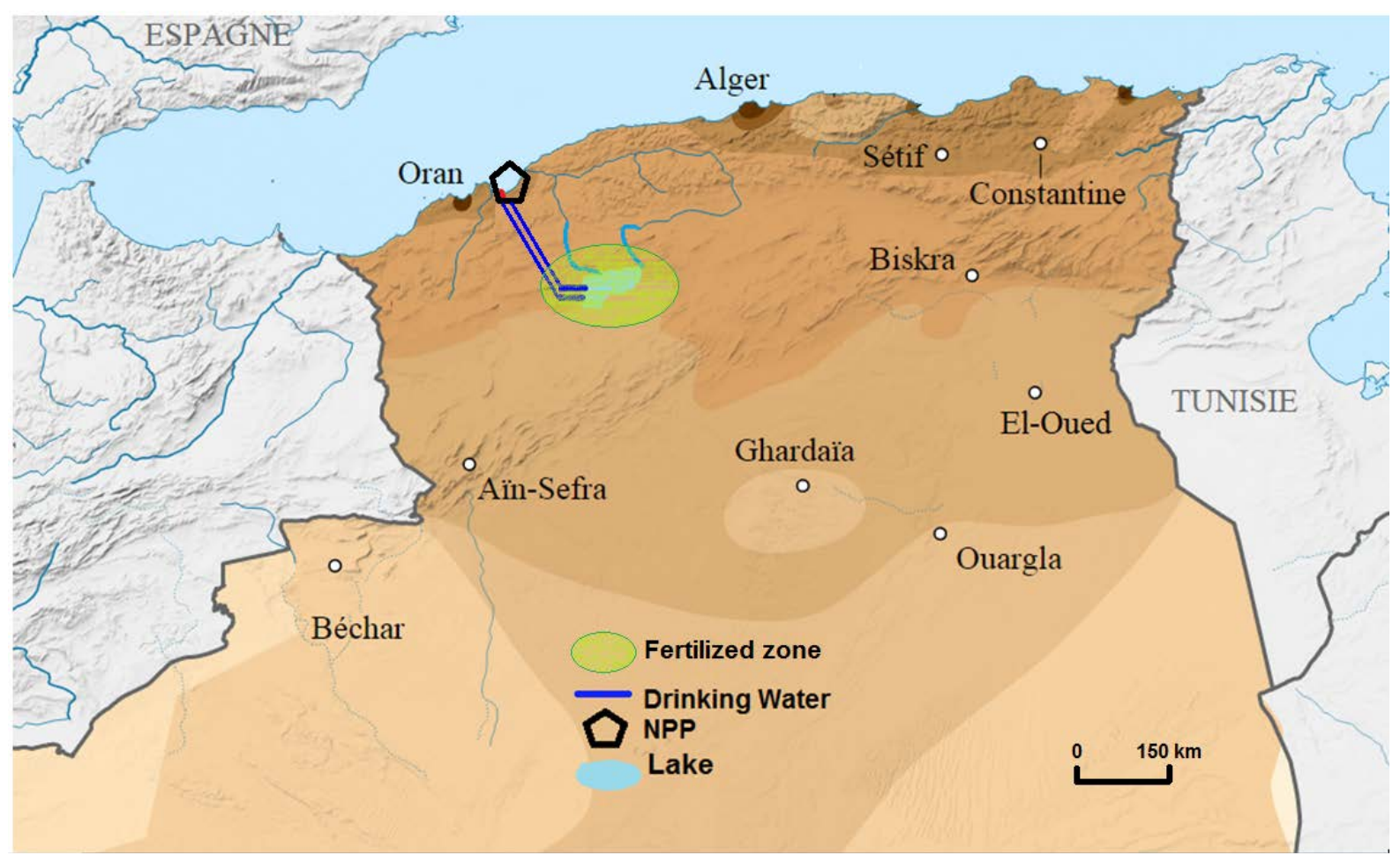

Figure 2. Dry desert lake fed by NPP desalinated sea water.

Table 2. Main targets for the analysis.

Geographical data

Quantity

Population that constitutes the civilization

Distance from the coastal site to the open air lake

(suitable pipelines must be built along this distance) Lake surface

Length of the river (i.e. between the lake and the ocean)

Distance between the mouth of the river and the coastal site

Percentage of African desert area involved

$\cong 5$ million

$>100 \mathrm{~km}$

$>100 \mathrm{~km}^{2}$

$>200 \mathrm{~km}$

$>100 \mathrm{~km}$

$<0.1 \%$

Table 3. Main assumptions adopted in the analysis.

Resource data

Quantity

Water needed to fertilize $104 \mathrm{~m}^{2}$ of desert land per year

Number of peoples that can be fed by the food produced per each $104 \mathrm{~m}^{2}$ of fertilized land

Unit reference Nuclear Steam Supply System power (Unit power per NSSS)

Desalination plant Gained Output Ratio (GOR)*

Fraction of desalinate water lost by evaporation from the river and the lake

Pro-capita thermal power consumption required for needs "other than agriculture"

Reference plant thermodynamic efficiency
$3 \times 10^{3} \mathrm{~m}^{3}$

5

4500 MWth

17

$50 \%$

$1.7 \mathrm{kw}$

$35 \%$

*GOR = ratio between flow-rate of produced desalinated water and flow-rate of steam entering the desalination plant. GOR equal to 17 is representative of the current state of the art.

Table 4. Main results of the analysis.

Geographical data

Desalinated water production rate per year

Area of desert land that can be cultivated

Number of reference NSSS units needed for agriculture (desalination and desalinated water pumping power)

Number of reference NSSS units needed for energy "other than agriculture"

Total number of reference NSSS units

\section{Quantity}

$1.3 \times 10^{9} \mathrm{~m}^{3}$

$2300 \mathrm{~km}^{2}$

4.5

1.9

7 
tended in order to achieve a proper energy mixing. However, the current share of the nuclear energy source appears regrettably small. Occurred or potential nuclear accidents should be given no role in the reasonable planning of the share for energy sources. The number of fatalities and the environmental impact, unavoidably associated with any energy source, must be at the basis for designing a consistent share of energy sources. The actual cost of energy should have a role inside a broader context where the available natural resources and the level of technological development of individual countries are properly considered. Advantages of the nuclear energy applications over competing energy sources in the area of electricity generation have been pointed out. Overall technological development has been associated to the exploitation of the nuclear power. Quality assurance and safety constitute industry related discipline that has been largely developed following nuclear energy uses.

Therefore nuclear technology can be profitably exploited to create new civilizations. The paper illustrates a possibility to create a river in the desert, "powered" by a suitable number of remote coastal nuclear power plants. This will allow the creation of conditions for the growth of an agriculture self-sustained society.

\section{Acknowledgements}

This work was carried out for the "E. Fermi and Nuclear Energy" conference, held in Pisa (I), October 15-16, 2001.

\section{References}

[1] IAEA-TECDOC-574 (1990) Use of Nuclear Reactors for Seawater Desalination.

[2] IAEA-TECDOC-1326 (2002) Status of Design Concepts of Nuclear Desalination Plants.

[3] D’Auria, F., Glaeser, H., Kim, M. (2014) A “New” Vision for Nuclear Reactor Safety. 3rd International Scientific and Technical Conference “Innovative Designs and Technologies of Nuclear Power” (ISTC NIKIET-2014), Moscow, 7-10 October 2014.

[4] Inhaber, H. (1977) Is Solar Power More Dangerous than Nuclear? IAEA Bulletin, 21, 11-17.

[5] OECD/NEA N. 6861 (2010) Comparing Nuclear Accident Risks with Those from Other Energy Sources.

\section{Submit or recommend next manuscript to SCIRP and we will provide best service for you:}

Accepting pre-submission inquiries through Email, Facebook, LinkedIn, Twitter, etc.

A wide selection of journals (inclusive of 9 subjects, more than 200 journals)

Providing 24-hour high-quality service

User-friendly online submission system

Fair and swift peer-review system

Efficient typesetting and proofreading procedure

Display of the result of downloads and visits, as well as the number of cited articles

Maximum dissemination of your research work

Submit your manuscript at: http://papersubmission.scirp.org/ 